\author{
Abstracta Iranica \\ Abstracta Iranica Revue bibliographique pour le domaine irano-aryen \\ Volume 42-43 | 2021 \\ Comptes rendus des publications de 2019-2020
}

\title{
Hayedeh Torabi. "Cyrus the Great and his "Perpetual Audience"”
}

\section{Benjamin Dromard}

\section{(2) OpenEdition}

10 Journals

\section{Édition électronique}

URL : https://journals.openedition.org/abstractairanica/52794

DOI : 10.4000/abstractairanica.52794

ISSN : 1961-960X

Éditeur :

CNRS (UMR 7528 Mondes iraniens et indiens), Éditions de l'IFRI

\section{Référence électronique}

Benjamin Dromard, «Hayedeh Torabi. "Cyrus the Great and his "Perpetual Audience"'” », Abstracta Iranica [En ligne], Volume 42-43 | 2021, document 43, mis en ligne le 30 juillet 2021, consulté le 12 décembre 2022. URL : http://journals.openedition.org/abstractairanica/52794; DOI : https://doi.org/ 10.4000/abstractairanica.52794

Ce document a été généré automatiquement le 12 décembre 2022.

Tous droits réservés 


\title{
Hayedeh Torabi. "Cyrus the Great and his "Perpetual Audience""
}

\author{
Benjamin Dromard
}

\section{RÉFÉRENCE}

Hayedeh Torabi. "Cyrus the Great and his "Perpetual Audience"” in W. Sommerfeld (Hrsg.). Dealing with Antiquity: Past, Present \& Future - RAI Marburg. (AOAT 460). Münster : Ugarit Verlag, 2020, p. 439-450.

1 La question du cylindre de Cyrus et de sa postérité contemporaine demeure prégnante. Il est devenu un élément primordial du récit national de l'Iran contemporain et ce depuis sa mobilisation par le régime des Pahlavi. On peut penser à la cérémonie célébrant 2500 ans de monarchie iranienne en 1971 à Persépolis comme exemple de cette propagande, reprise depuis dans une certaine mesure par une partie de la diaspora iranienne et par le régime de la République Islamique. Mohammed Rezâ Shâh inscrivit alors son exercice du pouvoir dans la continuité de l'empire achéménide. Se réclamer de Cyrus, c'est ainsi s'approprier l'héritage d'un empereur idéal. Le fameux cylindre en représentait un symbole positif : il s'agirait en effet de la première déclaration des droits de l'homme, faisant acte du refus de l'esclavage dans son empire et de la libération des peuples opprimés en Babylonie sous l'empire néo-babylonien. Tout ceci est une fabrication postérieure en vue de la création d'un récit national. L'autrice, dans cet article, reprend ces éléments et établit la chronologie de la création de cette lecture du cylindre de Cyrus. Celle-ci s'est construite notamment sur deux cas de falsification académique : une traduction ajoutant plusieurs lignes de texte, révélée au public dans un article de 2008 du Spiegel; une autre créée par un assyriologue chinois, présenté en 1985 à Oxford.

2 Hayedeh Torabi interroge ainsi la pertinence de la reprise de ce discours établi et maintenu par différents gouvernements au sein de la diaspora iranienne mais aussi par différents intellectuels. Si l'on comprend bien l'utilité de ce discours alors pour le 
pouvoir des Pahlavi (se présentant comme modèle au Moyen-Orient et tenter d'invisibiliser la répression politique qu'il exerçait) et pour la République Islamique (qui partage aussi le caractère nationaliste du précédent régime), que des historiens et autres savants s'approprient ce discours paraît extrêmement problématique. L'autrice présente clairement le cylindre de Cyrus et les raisons de son écriture au moment de la conquête de la Babylonie, qui s'ancre dans le conflit entre le clergé babylonien et le roi Nabonide et permet ainsi de légitimer le nouveau pouvoir achéménide sur la région. Elle en rappelle ainsi le contexte d'écriture et le sépare de ses utilisations modernes. Il est intéressant d'ailleurs de constater que Cyrus et sa présentation comme modèle idéal $\mathrm{du}$ souverain est largement absent de la littérature persane médiévale. C'est notamment le cas dans le Shāhnāmeh de Ferdowsi, qui utilise pourtant de nombreuses références à l'Iran pré-islamique. C'est par la redécouverte du texte par les disciplines naissantes de l'assyriologie et de l'étude de l'Iran antique dans les pays occidentaux que cette représentation de Cyrus va se constituer. L'apparition d'un nationalisme iranien va en accentuer l'émergence, sous l'influence d'un pan des études iraniennes orientalistes (notamment en Allemagne dans l'entre-deux-guerres) et certaines considérations racistes tentant de créer des liens entre les peuples « aryens » d'Europe et l'Iran.

3 L'autrice présente comme hypothèse l'idée que le ton assez général du texte, ancré dans la rhétorique des inscriptions royales mésopotamiennes, expliquerait en partie la facilité avec laquelle ce texte a pu être mobilisé. L'article présente ainsi une excellente synthèse consacrée à ce document et à sa mobilisation dans le débat contemporain.

\section{AUTEURS}

\section{BENJAMIN DROMARD}

Université Paris 1 Panthéon Sorbonne 